\title{
Experimental Development of Dual Phase Steel Laser-arc Hybrid Welding and its Comparison to Laser and Gas Metal Arc Welding
}

\author{
Wagner Duarte Antunes ${ }^{1}$, Milton Sergio Fernandes de Lima ${ }^{1,2}$ \\ 1 Instituto Tecnológico de Aeronáutica - ITA, Mechanical and Aeronautical Engineering Program, São Jose dos Campos, SP, \\ Brazil. \\ 2 Instituto de Estudos Avançados - IEAv, Photonics Division, São Jose dos Campos, SP, Brazil.
}

Received: 26 May, 2016

Accepted: 12 Sept., 2016

E-mails: wagner.eng@gmail.com (WDA), msflima@gmail.com (MSFL)

\begin{abstract}
Dual phase DP600 steels have been used in many automobile structures and laser welding has been the standard method for the joining of different sections. This work proposed a comparison between laser welding with arc welding (GMAW) and with hybrid laser-arc welding in order to access the microstructures and the mechanical behavior. The laser and hybrid welds are competitive in terms of microstructure and mechanical behavior, presenting both acceptable and tough welds. The maximum ductility of the laser and hybrid welds are very similar, around $14 \%$, and near to the values observed in the base material. The GMAW presents low ductility due to the softening caused by tampering of the martensite, and thus is unacceptable as the welding procedure.
\end{abstract}

Key-words: Laser beam welding; Hybrid laser-GMAW welding; GMAW welding; Dual phase steels.

\section{Introduction}

Advanced high strength steels (AHSS) have been extensively used in many industrial sectors and in particular in the automobile body structures [1]. Different compositions and different thermo-mechanical procedures produce AHSS with very different mechanical behavior, for example, with a tensile strength between 400 and $1000 \mathrm{MPa}$ and total elongation between 1 and 50\% [1]. Dual phase (DP) steels are a type of AHSS with wide acceptance in the car factories because the same class of steel can be tailored to be used as roofs, frames, pillars, among many other parts.

The microstructure of DP steels was designed to obtain a good balance between a ductile phase, ferrite, and a hard phase, martensite, in order to attain a given mechanical behavior [2]. This well balanced microstructure is lost during welding, because the fusion zone (FZ) and heat-affect zone (HAZ) are rapidly cooled from the austenite range. Generally DP steels presents a martensitic FZ which severely limits its formability [3]. Additionally, the HAZ presented a softened region next to the fusion line (FL) where the martensite is tempered. It is known that the presence of a soft HAZ severely limits the applicability of DP tailored welded blanks in automobile construction [4].

In order to reduce tempering of martensite, high energy density methods like laser beam welding have been used for DP steel welding [5]. Laser beam welding produces narrow $\mathrm{FZ}$ and with very limited $\mathrm{HAZ}$ and also the process productivity, giving by number of parts per hour, is much higher than any other welding method. However, the laser technology still suffered from two main drawbacks: the price of laser workstations and the dimensional tolerances for the blanks and the joint. The laser price is more than ten times higher than conventional arc machine and the parts to be welded must be aligned at the micrometer range.

This work intends to compare three welding methods: GMAW-Gas Metal Arc Welding, laser beam welding (LBW) and hybrid laser welding in order to access the microstructure and mechanical behavior after the welding of a DP600 steel plate. The study is useful to compare the laser technology to a cheaper alternative (GMAW) and a hybrid process conjugating arc and laser together. This latter has been reported to be more advantageous in terms of tolerances, thus keeping the intrinsic advantages of laser processing.
This is an Open Access article distributed under the terms of
the Creative Commons Attribution Non-Commercial Licens which permits unrestricted non-commercial use, distribution and reproduction in any medium provided the original work is properly cited. 


\section{Materials and Experimental Procedures}

\subsection{Base material}

The base material is a Dual Phase DP600 sheet with $2.16 \mathrm{~mm}$ thickness and composition given in Table 1.

Table 1. Chemical composition of the initial material in wt.\%. Fe is the balance.

\begin{tabular}{ccccccccc}
\hline $\mathbf{C}$ & $\mathbf{S i}$ & $\mathbf{M n}$ & $\mathbf{C u}$ & $\mathbf{N i}$ & $\mathbf{C r}$ & Mo & $\mathbf{N b}$ \\
0.076 & 0.017 & 1.67 & 0.015 & 0.017 & 0.023 & 0.16 & 0.010 \\
\hline $\mathbf{A l}$ & $\mathbf{N}$ & $\mathbf{P}$ & $\mathbf{S}$ & $\mathbf{M g}$ & $\mathbf{T i}$ & $\mathbf{W}$ & $\mathbf{V}$ \\
0.032 & 0.0052 & 0.016 & 0.048 & $<0.005$ & $<0.005$ & $<0.005$ & $<0.005$ \\
\hline
\end{tabular}

The sheet was produced by hot rolling followed by rapid quenching and cold rolling to the final thickness. An electro galvanized coating was applied by immersion of the sheet into a pot of $\mathrm{Zn}$ at $460^{\circ} \mathrm{C}$. During galvanizing, the sheets were heated to $550^{\circ} \mathrm{C}$ for 20 seconds and then cooled down to ambient temperature at $30^{\circ} \mathrm{C} / \mathrm{s}$. The final coating is a $\mathrm{Zn}-14 \% \mathrm{Fe}$ alloy with a density of $37 \mathrm{~g} / \mathrm{m}^{2}$, or about $5 \mu \mathrm{m}$ thickness. The coating around the edges to be welded was removed with a steel brush.

Figure 1 presents the initial material microstructure composed by ferrite (light gray phase) and martensite (dark gray phase). According to the AXIOVISION ${ }^{\circledR}$ automatic software analysis the amount of ferrite is $79 \pm 3 \%$.

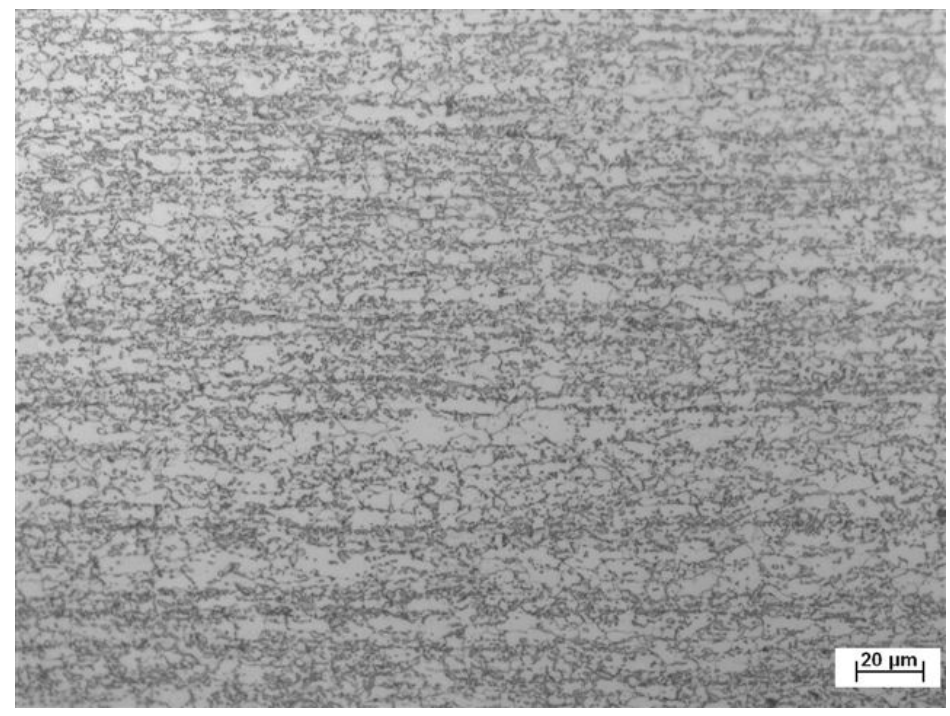

Figure 1. The initial material microstructure.

Each sheet was electro-sparked machined measuring $100 \mathrm{~mm} \times 200 \mathrm{~mm}$ to compose a final welded set measuring $200 \mathrm{~mm} \times 200 \mathrm{~mm}$.

\subsection{GMAW}

A mechanized Lincoln Electric arc welder model Idealarc Pulse Power 500 was used for GMAW. The process parameters were $400 \mathrm{~mm} / \mathrm{min}$ speed, $148 \mathrm{~A}$ current, $18 \mathrm{~V}$ voltage, wire feeding rate of $3 \mathrm{~m} / \mathrm{min}$ and $100 \% \mathrm{CO}_{2}$ gas at $9 \mathrm{l} / \mathrm{min}$ flow rate. The wire was a class S6 Lincoln Electric following ASME AWS SFA5.8. The wire composition was approximately C $=0.086 \% ; \mathrm{Mn}=1.57 \% ; \mathrm{Si}=0.86 \% ; \mathrm{S}=0.012 \% ; \mathrm{P}=0.014 ; \mathrm{Cu}=0.018 \% ; \mathrm{Ni}=0.019 \% ; \mathrm{Cr}=0.016 \%$; Mo $=0.006 \%$. 
Experimental Development of Dual Phase Steel Laser-Arc Hybrid Welding and its Comparison to Laser and Gas Metal Arc Welding

\subsection{Laser}

The laser welding was carried out using a YLR-2000 model IPG Photonics laser with maximum power of $2 \mathrm{~kW}$. The laser possesses a $100 \mu \mathrm{m}$ optical fiber with beam quality of $\mathrm{M}^{2}=12$. The displacement of the part to be welded is realized by a CNC x-y-z with $50 \mu \mathrm{m}$. The welding speed was $6 \mathrm{~m} / \mathrm{min}$ with the laser focus on the sheet surface and $2 \mathrm{~kW}$ of laser power. A pure argon shielding with $8 \mathrm{l} / \mathrm{min}$ feed protects the fusion zone. The laser welds were realized autogenously.

\subsection{Hybrid}

Hybrid GMAW plus laser welds were realized by a TRUMPF TruLaser Robot 5020 and an A-4600 Wels FRONIUS arc source. A $200 \mu \mathrm{m}$ core optical fiber delivered $6 \mathrm{~kW}$ continuous power at $6 \mathrm{~m} / \mathrm{min}$ welding speed. The laser beam quality $\mathrm{M}^{2}$ was 13.5 . The wire used in hybrid welding is the same of GMAW with a feeding speed of $4 \mathrm{~m} / \mathrm{min}$. The arc current and voltage was $141 \mathrm{~A}$ and $15.7 \mathrm{~V}$, respectively. The shielding gas was argon with $4 \%$ oxygen at $15 \mathrm{l} / \mathrm{min}$ flow rate.

\subsection{Analyses}

After welding the samples were cut in transversal section, hot mounted in resin and diamond polished up to $1 \mu \mathrm{m}$ mesh. The polished surfaces were etched using Nital 2\% (2\% nitric acid in ethanol), cleaned and then analyzed in a Zeiss optical microscope, model Imager2.

The hardness testing was carried out in a FutureTech Vickers Hardness equipment, model FM 800, using a 200 gf load per 10 seconds.

The tensile mechanical testing used an EMIC equipment, model DL 10.000, with a load cell of $250 \mathrm{kN}$. The applied standard was ASTM E 8 [6] with a crosshead velocity of $5 \mathrm{~mm} / \mathrm{min}$ and using a $50 \mathrm{~mm}$ gauge length extensometer. Every experimental condition was tested eight times in order to obtain statistical relevance. The important parameters to be evaluated are $\sigma_{\mathrm{y}}$ : yield strength at $0.2 \%$ plastic deformation; $\sigma_{\mathrm{m}}$ : maximum tensile strength; $\varepsilon_{\mathrm{u}}$ : uniform strain and $\varepsilon_{\mathrm{m}}$ : maximum strain before failure.

For each welding procedure, the temperatures in HAZ were evaluated using Sysweld ${ }^{\circledR}$ finite element software. The designed shape is the same of real samples and the properties database was for DP600 steel.

\section{Results and Discussion}

\subsection{Microstructure}

Figure 2a presents a general view of the GMAW weld with a fusion zone (FZ) composed by both base DP600 steel and the ASME AWS SFA5.8 wire. The columnar grains are visible and the microstructure is composed of white and gray constituents. Figure $2 \mathrm{~b}$ shows a more detailed picture of the microstructure composed by Widmanstätten ferrite (WF) and residual martensite (M). According to ImageJ image processing software, martensite accounted for $30 \%$ of the volume fraction.

Figure $2 \mathrm{c}$ presents the evolution of HAZ as a function of the distance from the FL. The HAZ could be divided into three sections, as follows: HAZ1 where the temperatures are sufficient to promote grain growth and, due to absence of filler dilution, martensite is the main constituent. HAZ2 is a region where the martensitic transformation is partial. HAZ3 belongs to the intercritical temperature range where the material was partially quenched to martensite and the original ferrite remained. The region marked BM in Figure $2 \mathrm{c}$ is the base material, where the temperatures were below A1. Although the BM region is microstructural uniform, tempering may occur, thus leading the original martensite be decomposed to ferrite plus carbides, leading to softening.

According to the FEM software, the boundaries between BM and HAZ3 and between HAZ3 and HAZ2 correspond to the lines $A 1$ and $A 3$, respectively, as calculated in a previous study [5]. The temperature profile will be presented in Section 3.3, together with the explanation about the tempering role in brittleness.

Figure 3a presents the macroscopic view of the laser welded DP600 steel. Compared to the GMAW (Figure 2a), the laser weld (Figure 3a) is narrower, measuring barely $0.4 \mathrm{~mm}$ in the middle of the sheet, and more uniform though the entire section. Figure $3 \mathrm{~b}$ shows the microstructure near to the middle of the weld. Columnar grains are 

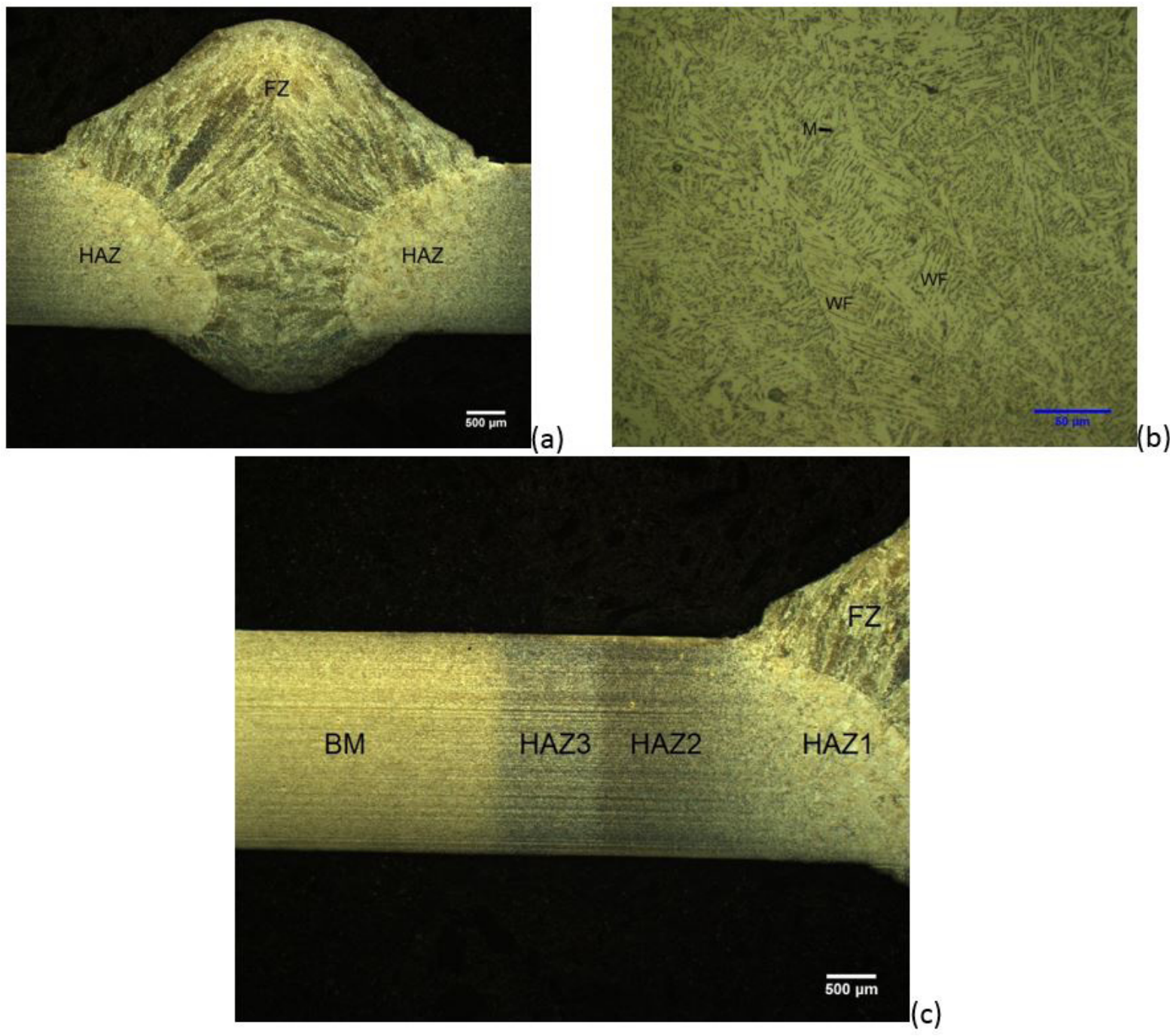

Figure 2. (a) General view of the a GMAW showing the fusion zone (FZ) and heat affected zone (HAZ); (b) The microstructure of the fusion zone for a GMAW weld; (c) Different heat-affected zones in a GMAW weld, HAZ1, HAZ2 and HAZ3, and the fusion zone (FZ) and the base material (BM).

visible as well as a very thin HAZ. The extension of HAZ is more visible with a larger magnification, as presented in Figure $3 \mathrm{c}$, measuring around $50 \mu \mathrm{m}$. Both FZ and HAZ are composed of martensite plates, being finer in the HAZ because of solid-state reaction. The estimated temperatures within the HAZ of Figure $3 \mathrm{c}$ varied from liquidus $\left(1689{ }^{\circ} \mathrm{C}\right.$ [5]) to approximately $1200{ }^{\circ} \mathrm{C}$. Below $1200^{\circ} \mathrm{C}$, the time was insufficient to produce any visible phase transformation because of high laser speed $(6 \mathrm{~m} / \mathrm{min})$.

Figure 4a presents the cross-section macrostructure of a hybrid weld with dimensions between GMAW (Figure 2a) and LBW (Figure 3a). The width of FZ in the middle of the sheet was $1 \mathrm{~mm}$. Since the wire dilution was less than GMAW, the microstructure is composed by a mixture of constituents such as martensite (M), grain boundary ferrite (FGB), Widmanstätten Ferrite (WF) and bainite (B), as presented in Figure $4 \mathrm{~b}$. In Figure $4 \mathrm{c}$ the HAZ is presented together with the temperature profile given by Sysweld ${ }^{\circledR}$. The $0.45 \mathrm{~mm}$ wide HAZ is composed of fine grains (Figure 4c) with martensitic plates formed in a temperature range between liquidus and approximately $1225^{\circ} \mathrm{C}$. Similar to laser welds, the laser-arc speed was too fast $(6 \mathrm{~m} / \mathrm{min})$ to allow any noticeable transformation below $1225^{\circ} \mathrm{C}$. 

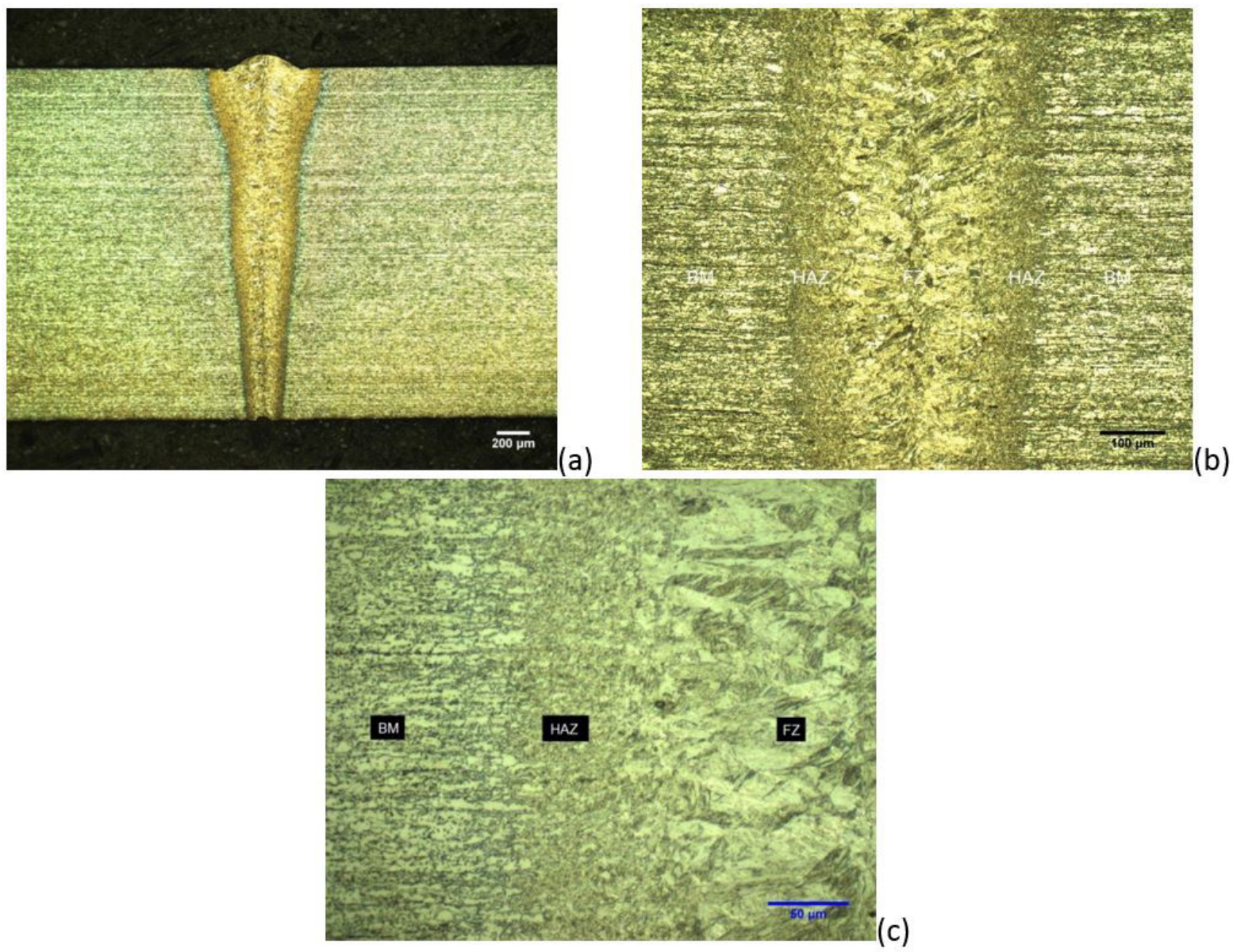

Figure 3. (a) Representative macrostructure of a laser weld; (b) Microstructure of the base material (BM), heat-affected zone (HAZ) and fusion zone (FZ) after laser welding; (c) Detail of the region around HAZ of a laser weld.

\subsection{Hardness}

In Figure 5 the Vickers hardness (HV) profiles for each condition are plotted against the distance from the welds centerlines (d). The fusion zone of the GMAW presented softer than the other conditions with hardness around $220 \mathrm{HV}$. The hardness in HAZ of the GMAW has shown a little increase to about $230 \mathrm{HV}$ and then a decrease to about $190 \mathrm{HV}$. For the GMAW, the increase in HV, located $3 \mathrm{~mm}$ from the centerline, corresponds to the middle of HAZ1 and the minimum in HV, located $5 \mathrm{~mm}$ from the centerline, corresponds to the middle of HAZ3 (Figure 2c). The higher hardness values were verified in laser welds, attaining $370 \mathrm{HV}$, due to very refined and martensitic grains. The Hybrid welds had an HV value below the laser because of the wire dilution. The HAZ of hybrid, marked by two shoulders in Figure 5, was harder than the weld because of solid-state martensite transformation.

\subsection{Tensile behavior}

Table 2 summarizes the most important tensile strength results for the current welds, compared to base material (BM) condition. The symbols $\sigma_{\mathrm{y}^{\prime}} \sigma_{\mathrm{m}^{\prime}} \varepsilon_{\mathrm{u}}$ and $\varepsilon_{\mathrm{m}}$ are the yield strength, tensile strength, uniform elongation and maximum elongation, respectively.

As can be seen in Table 2, all the welded coupons could be classified as DP600 standard since the tensile strength attained or surpassed $600 \mathrm{MPa}$. The slight reduction in yield strength for the high energy density welds compared to BM and GMAW does not affect the formability of the blanks. All BM, Laser and Hybrid coupons broke 

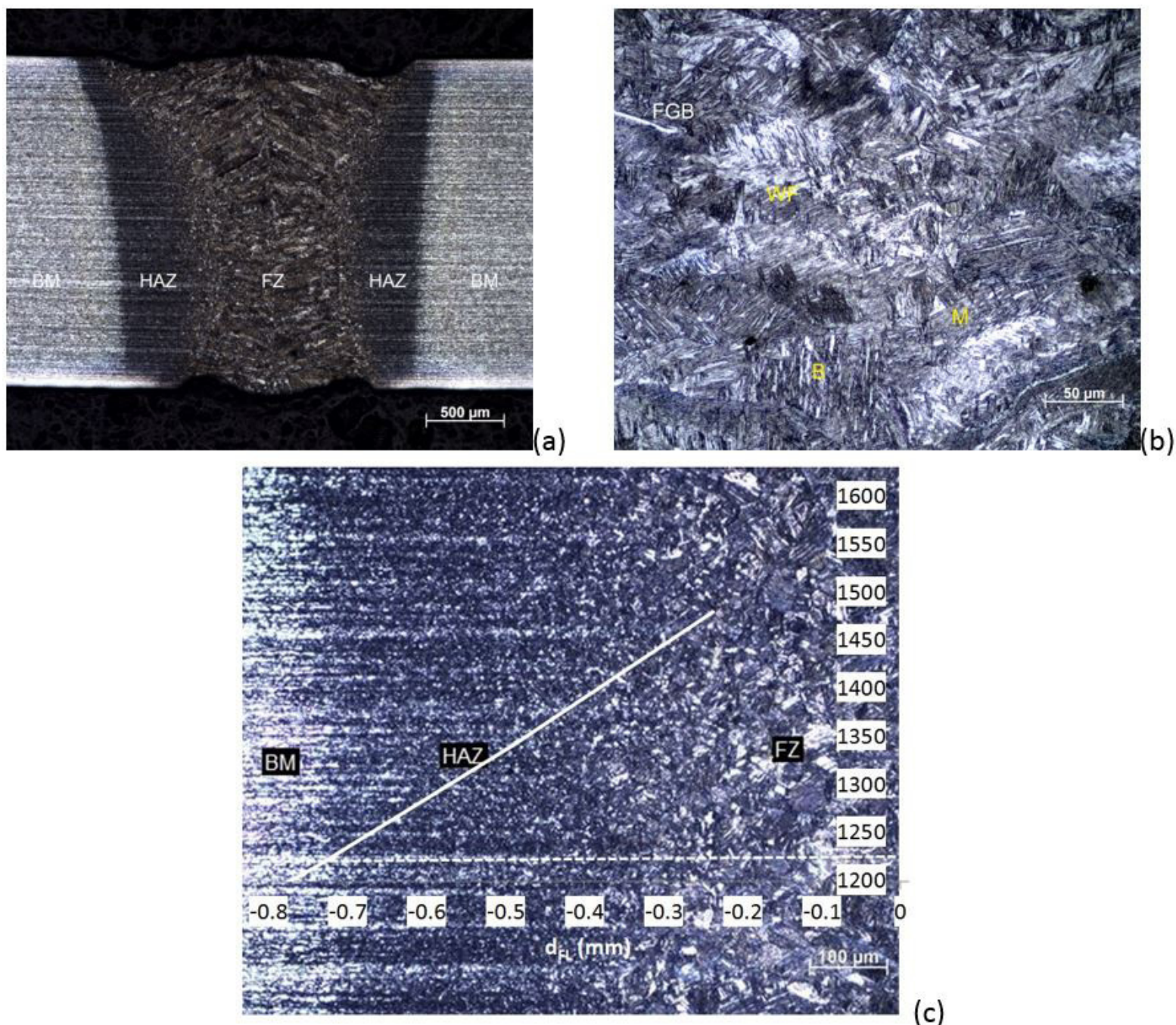

(c)

Figure 4. (a) Representative macrostructure of a hybrid weld; (b) The microstructure of the fusion zone for a hybrid weld; (c) Detail of the region around HAZ of a hybrid weld together with the temperature profile (straight line). $\mathrm{FZ}$ = fusion zone; $\mathrm{HAZ}=$ heat-affected zone and $\mathrm{BM}=$ base material.

Table 2. Summary of tensile strength results for each condition.

\begin{tabular}{cllcc}
\hline Condition & $\boldsymbol{\sigma}_{\mathbf{y}}(\mathbf{M P a})$ & $\boldsymbol{\sigma}_{\mathbf{u}}(\mathbf{M P a})$ & $\boldsymbol{\varepsilon}_{\mathbf{u}}(\%)$ & $\boldsymbol{\varepsilon}_{\mathbf{m}}(\%)$ \\
BM & $430 \pm 20$ & $630 \pm 20$ & $14.0 \pm 0.5$ & $16 \pm 1$ \\
GMAW & $440 \pm 10$ & $620 \pm 4$ & $5.5 \pm 0.1$ & $7.9 \pm 0.1$ \\
Laser & $370 \pm 10$ & $610 \pm 10$ & $11.1 \pm 0.6$ & $14.3 \pm 0.5$ \\
Hybrid & $390 \pm 10$ & $650 \pm 10$ & $10.7 \pm 0.3$ & $14.3 \pm 0.3$ \\
\hline
\end{tabular}

somewhere in the base material. However, the very high loss of ductility in GMAW case compared to the other samples is a major threat, since it impacts directly on the toughness of the welded plates.

The loss of ductility in GMAW was linked to a premature breakage occurring about $9 \mathrm{~mm}$ from the fusion line, as presented in Figure 6 . The localized striction of $78 \%$ occurred because of the tempering of base material martensite.

In order to illustrate the maximum temperature attained in each region, a temperature plot is superposed to the picture in Figure 6 . The boundaries between $\mathrm{A} 1$ and $\mathrm{A} 3$ temperatures regions are well marked, as well as the temperature for Tempering of Ferrous Martensite (TFM). TFM is approximately $450{ }^{\circ} \mathrm{C}$ in the present case, 
Experimental Development of Dual Phase Steel Laser-Arc Hybrid Welding and its Comparison to Laser and Gas Metal Arc Welding

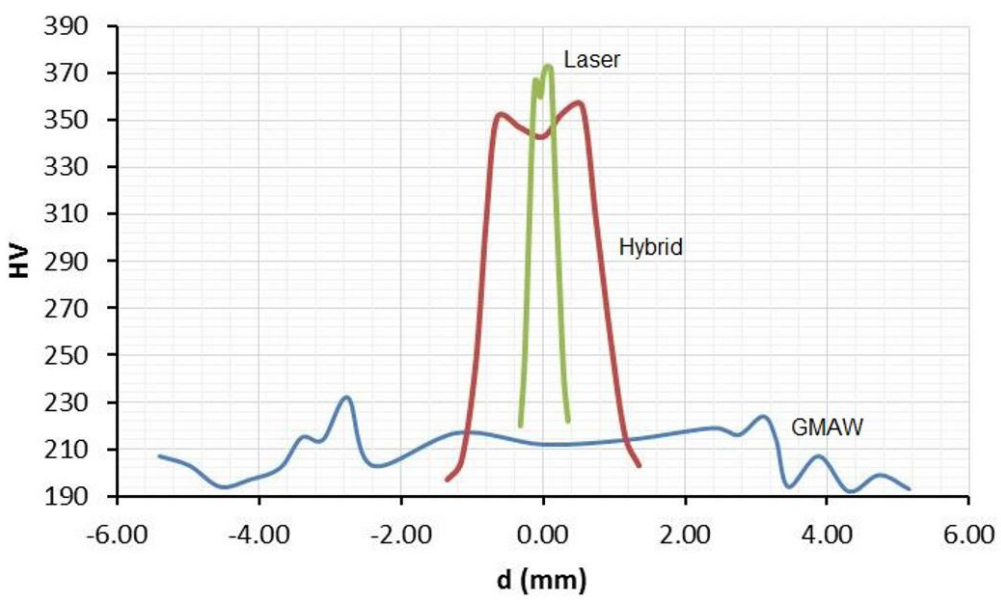

Figure 5. Vickers hardness as a function of the distance (d) from the weld centerline for the three processes.

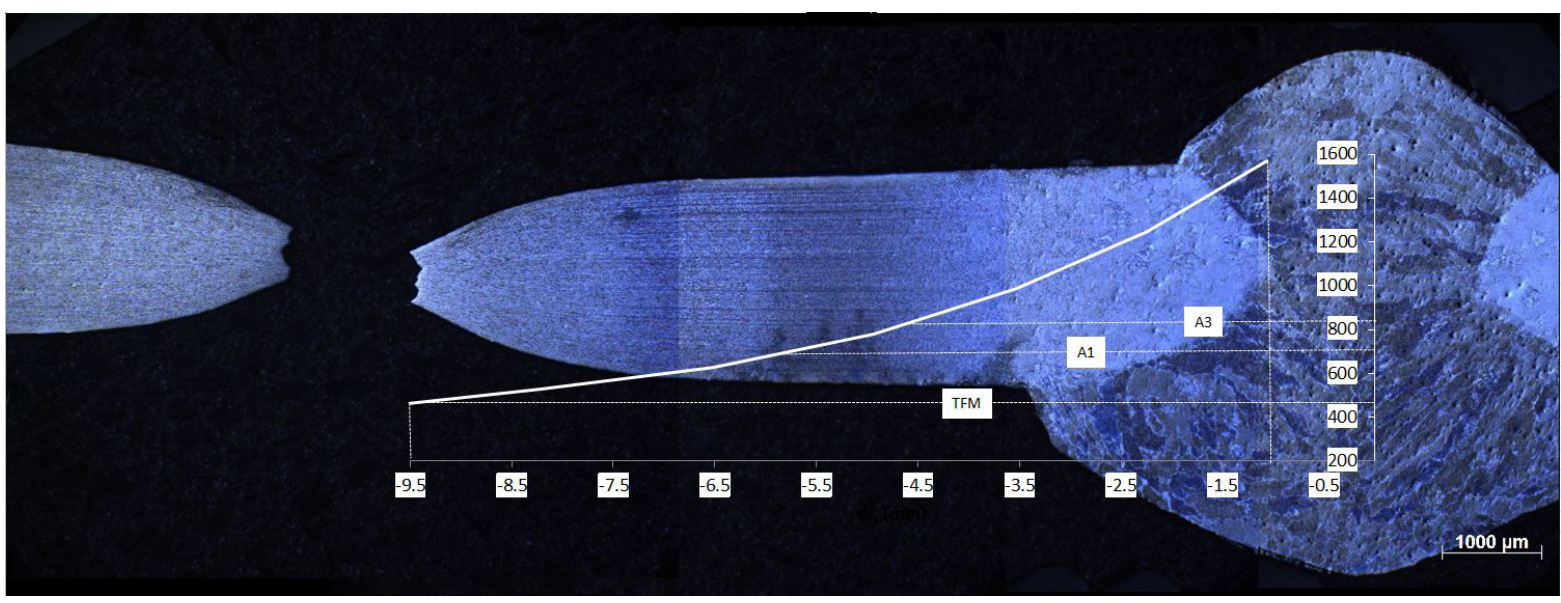

Figure 6. Failure region in a GMAW tensile coupon and the estimated maximum temperature attained.

corroborating the data from Porter and Easterling [7]. Therefore, the excess thermal load is the main cause of reduced toughness in GMAW.

The high hardness values of the FZ for laser and hybrid cases, Figure 5, did not affect the tensile behavior since all coupons broke in BM.

\section{Remarks}

Considering the intrinsically low ductility of GMAW, both laser and hybrid sourced are eligible for the DP600 steel sheet welding. The productivity of both processes is similar, since the welding speeds are the same, $6 \mathrm{~m} / \mathrm{min}$. Additionally, the beam qualities $\left(\mathrm{M}^{2}\right)$ are almost the same, thus the keyhole stability, related to the defect formations, may be the same. However, the hybrid workstation possesses a laser resonator of $6 \mathrm{~kW}$ compared to $2 \mathrm{~kW}$ of the ordinary laser system. This fact, together with a the need an additional arc and filler wire equipment, leads to a higher cost for the hybrid compared to the single laser. If the cost of an GMAW equipment in Brazil is the unity, the cost of the laser workstation may be 1'600 and the hybrid equipment will be around 5'100. The use of hybrid technique instead of single laser source could be justified by an addition of material (wire), which locally increases the thickness of the sheet, and also with the possibility to fill the grooves. In any other case, the ordinary laser welding equipment is sufficient to weld sheets of DP600 steel. 


\section{Conclusions}

The following conclusions can be drawn:

The microstructure of GMAW was composed by Widmanstätten ferrite plus residual martensite due to the high dilution of the filler wire and presents a low hardness value, around $220 \mathrm{HV}$.

The microstructure of the laser welds was marked by martensite, which conferred a high hardness value of $370 \mathrm{HV}$.

The wire dilution is less marked in the microstructure of the hybrid welds which presented martensite, bainite and ferrite, and the hardness attained $350 \mathrm{HV}$.

The tensile strengths of all welds are similar, however the ductility of the GMAW is much lower compared to the laser and hybrid welds. The low toughness of the GMAW was linked to the tempering which occurs around $450^{\circ} \mathrm{C}$ in the present case.

Considering both productivity, tensile behavior and costs, the laser workstation is the best choice to weld sheets of DP600 steel.

\section{Acknowledgements}

One of the authors (WDA) thanks Coordenação de Aperfeiçoamento de Pessoal de Nível Superior (Capes) for a scholarship. Thanks are also due to Centro de Tecnologia SENAI-RJ for the hybrid welding experiments.

\section{References}

[1] Dolfi J. Advanced high strength steel (AHSS) weld performance study for autobody structural components. Southfield: Auto/ Steel Partnership Joining Project; 2006.

[2] Davies RG. Influence of martensite composition and content on the properties of dual phase steels. Metallurgical Transactions A: Physical Metallurgy and Materials Science. 1978;9(5):671679. http://dx.doi.org/10.1007/BF02659924.

[3] Xia MS, Kuntz ML, Tian ZL, Zhou Y. Failure study on laser welds of dual phase steel in formability testing. Science and Technology of Welding and Joining. 2008;13:378-387.

[4] Kang J, Ososkov Y, Embury JD, Wilkinson DS. Digital image correlation studies for microscopic strain distribution and damage in dual phase steels. Scripta Materialia. 2007;56(11):999-1002. http://dx.doi.org/10.1016/j.scriptamat.2007.01.031.

[5] Correard GCC, Miranda GP, Lima MSF. Development of laser beam welding of advanced high-strength steels. International Journal of Advanced Manufacturing Technology. 2016;83(912):1967-1977. http://dx.doi.org/10.1007/s00170-015-7701-2.

[6] American Society for Testing and Materials. ASTM E8/E8M-15a: standard test methods for tension testing of metallic materials. West Conshohocken: ASTM; 2016 [access 01 May 2016]. Avaliable from: http://www.astm.org/Standards/E8.htm

[7] Porter DA, Easterling KE. Phase transformations in metals and alloys. 2nd ed. London: Chapman \& Hall; 1992. 